\title{
ANÁLISE DE PH, TURBIDEZ, COLIFORMES TOTAIS E ESCHERICHIA COLI DA ÁGUA DA REDE DE ABASTECIMENTO PÚBLICO DO MUNICÍPIO DE ALTA FLORESTA D'OESTE - RO.
}

ALISSON SABAI DA SILVA - sabai10@ hotmail.com

Faculdades Integradas de Cacoal - UNESC

ANDRÉ DA SILVA COSTA - andrecosta@ unescnet.com

Faculdades Integradas de Cacoal - UNESC

DENNER MANTHAY POTIN - dennerpotin@gmail.com

Universidade Federal Rural de Pernambuco - UFRPE

ANTÔNIO LUCIANO VOLPATO ALVES - volpatus@gmail.com

Faculdades Integradas de Cacoal - UNESC

LILA FRANCISCA DE OLIVEIRA REIS MATOS - lila@ unescnet.br

Faculdades Integradas de Cacoal - UNESC

DAIENNE MANTHAY POTIN - daiennempotin@ outlook.com

Faculdades Integradas de Cacoal - UNESC 


\section{Resumo}

A água é um dos elementos mais essenciais para os seres vivos e é utilizada para inúmeras finalidades. O objetivo desse trabalho foi analisar a qualidade da água da rede de abastecimento das residências no município de Alta Floresta D’Oeste - RO que é fornecida pelo Serviço de Abastecimento de Água e Esgoto (SAAE) e verificar se a mesma se encontra dentro dos padrões estabelecidos pela Portaria de potabilidade $\mathrm{n}^{\circ}$ 2.914/2011 do Ministério da Saúde. Foram coletadas 7 amostras diretamente de torneiras acopladas aos registros instalados nas casas pelo SAAE, sendo que uma amostra foi coletada na estação de tratamento. No laboratório das Faculdades Integradas de Cacoal UNESC foram realizados procedimentos para a verificação dos parâmetros de $\mathrm{pH}$, turbidez, coliformes totais e Escherichia coli. Para coleta das amostras, transporte e realização dos procedimentos foram seguidos métodos Manual Prático de Análise de Água da FUNASA. Dos parâmetros analisados, observou-se que os resultados obtidos para $\mathrm{pH}$, coliformes totais e E.coli se encontraram em conformidade com a Portaria MS $n^{\circ}$ 2.914/2011. Em relação à turbidez, 36\% das amostras analisadas apresentaram valores superiores de 5 UNT, não atendendo os padrões de potabilidade. Conclui-se que no período estudado a água fornecida para a população de Alta Floresta D’Oeste - RO não apresentou características satisfatórias em relação à turbidez.

Palavras chave: água, potabilidade, abastecimento, coliformes totais, turbidez.

\section{Introdução}

A água é um ingrediente essencial para vida, sendo ela um dos elementos mais preciosos que a terra nos oferece. Entretanto muitos países não têm essa visão ou consciência de buscar formas adequadas para que haja um gerenciamento correto desse recurso (NEVES, 2012).

O planeta Terra é coberto por água em $70 \%$ da sua proporção, porém, somente $2 \%$ desse total é água doce, que o homem pode utilizar para consumo, onde cerca de $97 \%$ dessa água doce se encontra no subsolo (ABAS, 2004). 


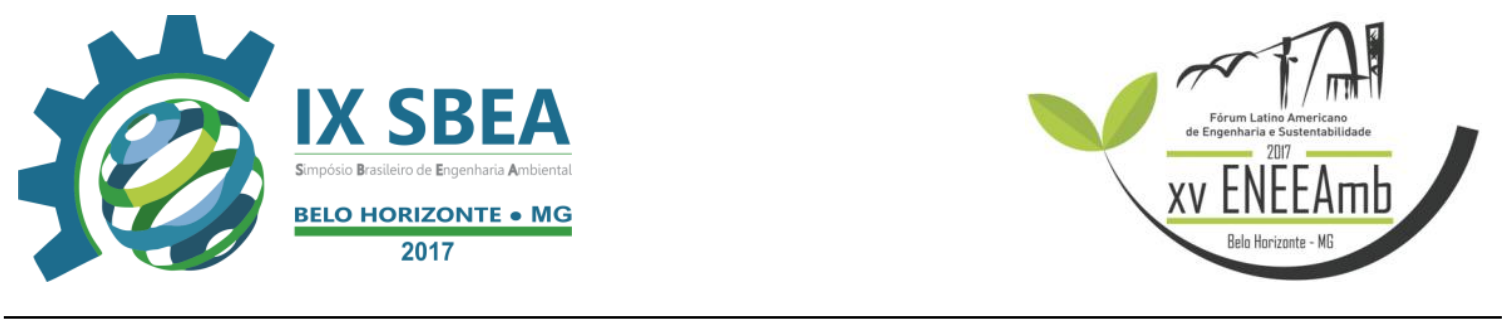

O Brasil se destaca quando o assunto é água doce, obtendo $12 \%$ desta água disponível no mundo, entretanto, o país tem sérios problemas com a degradação dos recursos hídricos e isso faz com que acarrete problemas também no tratamento e na distribuição, onde muitas casas não têm rede de abastecimento (MARQUES et al., 2010).

As diversas formas de desperdício de água com atividades domésticas podem estar diretamente relacionadas a falta de água em algumas regiões do Brasil, isso devido à falta de conscientização da população.

No Brasil, segundo a Organização Mundial de Saúde (2006), “morrem 29 pessoas ao dia por doenças decorrentes da qualidade da água e do não tratamento de esgotos, estima-se que cerca de $70 \%$ dos leitos dos hospitais estão ocupados por pessoas que contraíram doenças transmitidas pela água”. É indispensável saber que todos os seres humanos têm o direito ao acesso à água com boa qualidade, pois a água dentro dos patrões estabelecidos interfere diretamente na saúde pública.

A Portaria $n^{\circ} 2.914 / 2011$ do Ministério da Saúde em seu art. $5^{\circ}$, diz que a água para consumo humano é a água potável destinada à ingestão, preparação e produção de alimentos e à higiene pessoal, independente da sua origem.

A água do município de Alta Floresta D’Oeste - RO é controlada pelo Serviço de Abastecimento de Água e Esgoto (SAAE), onde o mesmo é responsável pela captação, tratamento e distribuição da água no município. O controle da água deve obedecer aos parâmetros estabelecidos pela Portaria MS n 2.914/2011 que determinam os padrões da qualidade da água.

O presente estudo teve como objetivo analisar a qualidade da água da rede de abastecimento das residências no município de Alta Floresta D’Oeste - RO e verificar se a mesma chega até as residências dentro dos padrões estabelecidos.

\section{Metodologia}

Foram escolhidos 7 (sete) pontos amostrais para a determinação dos parâmetros físico e químicos e microbiológicos, sendo escolhido 1 (um) ponto por bairro e uma amostra foi coletada na estação de tratamento. Foram coletadas amostras de água em 


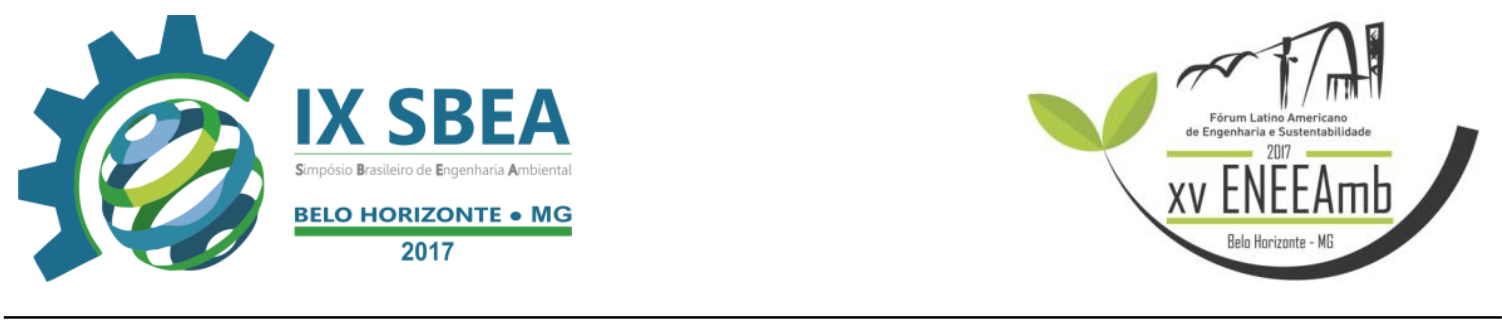

residências que utilizam à água que é fornecida pela rede de abastecimento do município de Alta Floresta D’Oeste - RO.

As coletas das amostras de água foram realizadas no dia 26 de junho e dia 15 de julho de 2015, seguindo a metodologia referente à coleta em residências que está descrito o Manual Prático de Análise de Água da FUNASA (2013), que é preconizado no Standard Methods for the Examination of Water and Wastewater (APHA, 1995).

Todas as amostras foram coletadas diretamente nas torneiras acopladas ao registro que o SAAE instala nas residências, ou seja, antes da água entre em contato com a caixa d'água. Segundo o Manual da FUNASA (2013), deve-se deixar a torneira aberta cerca de 3 minutos para que seja realizada a limpeza da tubulação de modo que não possa haver alterações nas características das amostras.

As amostras foram coletadas em frascos esterilizados em autoclave. Após as coletas, os frascos foram acondicionados em caixa de isopor com gelo, a uma temperatura de aproximadamente $4^{\circ} \mathrm{C}$ e, então, transportados ao Laboratório da UNESC - Faculdades Integradas de Cacoal, localizado no município de Cacoal - RO onde foi dada a sequência com os exames laboratoriais.

3.1 Variáveis analisadas no monitoramento da qualidade da água

A metodologia utilizada para as análises físico e microbiológicas seguiram as práticas e técnicas descritas no Manual Prático de Análise de Água da FUNASA (2013), que é preconizado no Standard Methods for the Examination of Water and Wastewater (APHA, 1995).

\subsubsection{Análises físico}

A variável de $\mathrm{pH}$ foi medida por meio de eletrodos, com o auxílio do equipamento pHmetro Hanna pH21, através do método potenciométrico.

A turbidez foi verificada através do método nefelométrico, com o auxílio do equipamento Turbidímetro adamo TB -1000. Esse método consiste em verificar a 


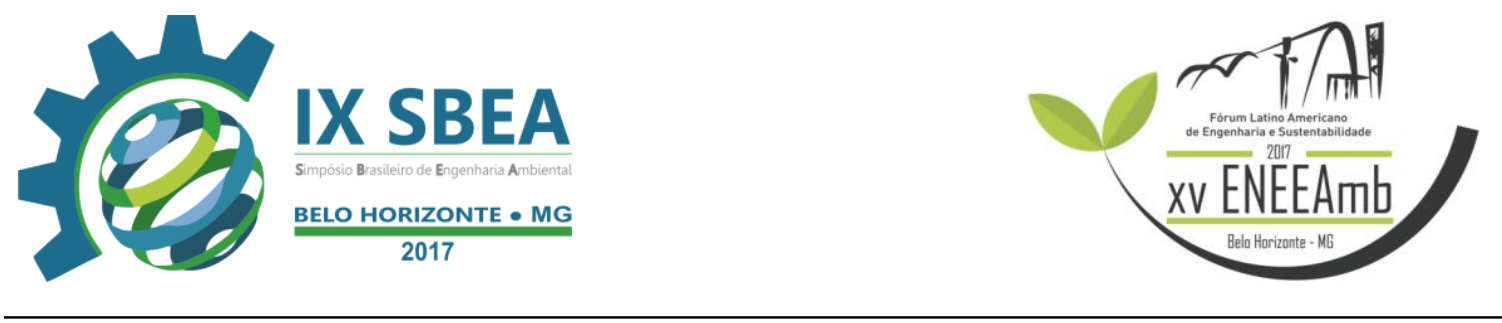

transparência da água, ou seja, verificar se ocorre à presença de substâncias em suspensão e o resultado é baseado na intensidade de luz que atravessa a água.

\subsubsection{Análises microbiológicas}

As análises microbiológicas foram realizadas pelo método de membrana filtrante, que com o auxílio de uma pinça de aço inox previamente flambada e fria, foi retirada a membrana filtrante de um cartão absorvente e em seguida colocada no porta-filtro. Então, agitou-se o frasco com a amostra e ao destampar foi flambada a boca do frasco.

A água da amostra $(100 \mathrm{~mL})$ passou com o auxílio de uma bomba a vácuo por uma membrana filtrante estéril com diâmetro de $0,47 \mathrm{~mm}$ e porosidade de $0,45 \mu \mathrm{m}$ que tem o intuito de reter microrganismos presentes nas amostras de água. Logo em seguida, cuidadosamente foi retirada a membrana do porta filtro com o auxílio da pinça inox e foi colocado na placa de Petri, com o lado quadriculado para cima, a placa de Petri foi tampada e incubada a $35^{\circ} \mathrm{C}$ durante 24 horas em uma estufa.

Após o período de incubação, foram feitas as leituras das placas para que pudesse verificar a existência ou não de colônias presentes sobre as membranas, onde a quantidade de bactérias foram demonstradas em unidade formadora de colônia por $100 \mathrm{~mL}$ (UFC/100mL).

\section{Resultados e Discussão}

\subsection{Análises físico}

Na Tabela 1 são apresentados os resultados das análises físico das amostras de água para consumo humano, realizadas no mês de junho e julho de 2015, na cidade de Alta Floresta D’Oeste - RO. 


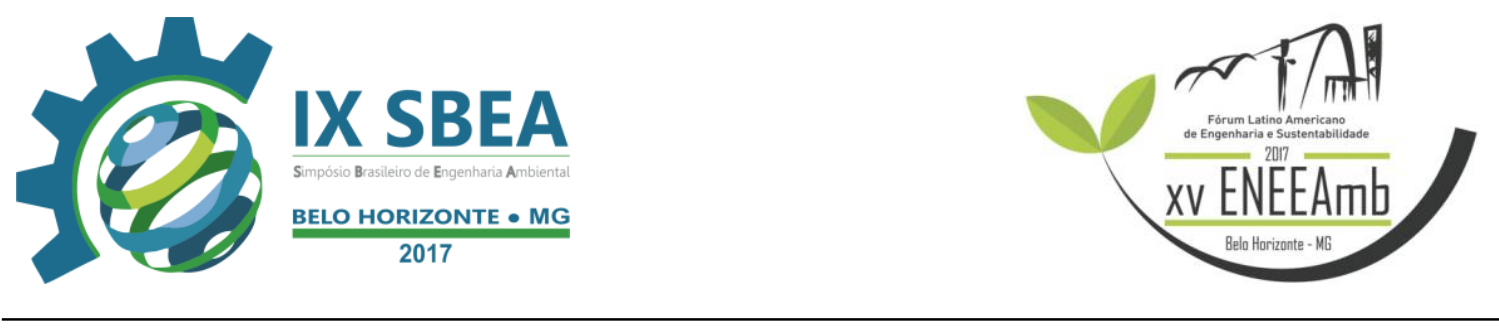

Tabela 1. - Resultados das análises de pH e Turbidez.

\begin{tabular}{|c|c|c|c|c|}
\hline \multirow{3}{*}{ AMOSTRAS } & \multicolumn{4}{|c|}{ PARÂMETROS } \\
\hline & \multicolumn{2}{|c|}{$\mathbf{p H}$} & \multicolumn{2}{|c|}{ TURBIDEZ (UNT) } \\
\hline & Junho & Julho & Junho & Julho \\
\hline $\begin{array}{l}\text { P1 - Estação de } \\
\text { Tratamento }\end{array}$ & 6,4 & 6 & 5 & 5,1 \\
\hline P2 - Bairro Cidade Alta & 6,6 & 6,2 & 4,9 & 4,9 \\
\hline P3 - Bairro Liberdade & 6,7 & 6,8 & 5,1 & 5 \\
\hline P4 - Bairro Centro & 7 & 6,5 & 4,9 & 5,1 \\
\hline $\begin{array}{l}\text { P5 - Bairro Santa } \\
\text { Felicidade }\end{array}$ & 6,9 & 6,3 & 5,2 & 4,8 \\
\hline P6 - Bairro Redondo & 6,8 & 6,7 & 5 & 4,8 \\
\hline $\begin{array}{l}\text { P7 - Bairro Princesa } \\
\text { Isabel }\end{array}$ & 6,6 & 6,7 & 5,1 & 4,7 \\
\hline Média & 6,7 & 6,4 & 5 & 4,9 \\
\hline
\end{tabular}

\subsubsection{Análise de Potencial Hidrogeniônico - pH}

Dos sete pontos em que foram realizadas as análises, $100 \%$ das amostras apresentaram valores dentro dos padrões estabelecidos na Portaria MS n 2.914/2011, que recomenda a faixa de $\mathrm{pH}$ entre 6 a 9,5.

$\mathrm{O}$ pH é a concentração de íons H+e OH-, ou seja, é a representação se uma solução está ácida ou alcalina. $\mathrm{O}$ pH pode sofrer diversas alterações sobre a sua qualidade hídrica, sendo elas alterações químicas (BAIRD, 2002). O valor do $\mathrm{pH}$ pode variar de 0 a 14 , onde uma água com um valor abaixo de 7 pode ser considerada ácida, neutra com valor igual a 7 e alcalina com valores acima de 7 .

Contudo, não foram observados valores abaixo do recomendado, assim evitando risco tanto para a saúde humana como para a rede de abastecimento, pois $\mathrm{pH}$ abaixo de 6 pode influenciar na corrosão da rede de abastecimento (LIBANIO, 2008).

\subsubsection{Análise de Turbidez}




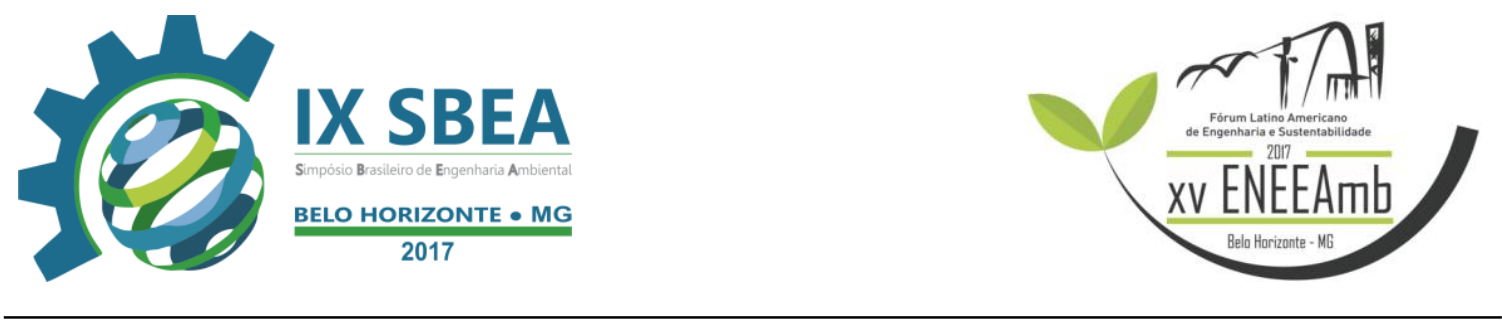

A média da turbidez encontrada no mês de junho foi de 5 UNT, sendo que $43 \%$ das análises realizadas estavam com os valores acima do recomendado pela Portaria MS $\mathrm{n}^{\circ}$ 2.914/2011. No mês de julho a média foi de 4,9 UNT e 29\% das análises realizadas também apresentaram valores acima do permitido pela portaria (Tabela 1), sendo que a mesma estabelece que em qualquer ponto da rede de distribuição o valor não ultrapasse de 5,0 UNT.

A turbidez é representada pela capacidade que um feixe de luz tem para atravessar uma amostra de água, onde a presença de sólidos em suspensão reduz a sua transparência, podendo ser provocado por partículas inorgânicas e matéria orgânica (HELBEL, 2011).

A turbidez elevada pode indicar a presença de sólidos em suspensão, como também pode estar relacionada à concentração de ferro. Onde a turbidez elevada pode interferir no processo de cloração, protegendo os microrganismos de ter contato com os desinfetantes e pode causar sabor indesejado.

\subsection{Resultados das análises microbiológicas}

\subsubsection{Análises de Coliformes totais e E. coli}

De acordo com a Tabela 2, pode-se verificar que $100 \%$ dos pontos de amostragem estavam em conformidade com a Portaria MS n 2.914/2011, onde a mesma estabelece a ausência de coliformes totais e E. coli em $100 \mathrm{~mL}$ de amostra de água tratada.

Tabela 2. - Resultados das análises de Coliformes totais e E. coli.

\begin{tabular}{l|c|c|c|c}
\hline & \multicolumn{3}{|c}{ PARÂMETROS } \\
\hline \multicolumn{1}{c|}{ AMOSTRAS } & $\begin{array}{c}\text { Coliformes totais (NMP/100 } \\
\text { mL) }\end{array}$ & \multicolumn{1}{c}{ E. coli (NMP/100 mL) } \\
\hline P1 - Estação de & Junho & Julho & Junho & Julho \\
Tratamento & Ausência & Ausência & Ausência & Ausência \\
P2 - Bairro Cidade Alta & Ausência & Ausência & Ausência & Ausência \\
P3 - Bairro Liberdade & Ausência & Ausência & Ausência & Ausência \\
P4 - Bairro Centro & Ausência & Ausência & Ausência & Ausência
\end{tabular}



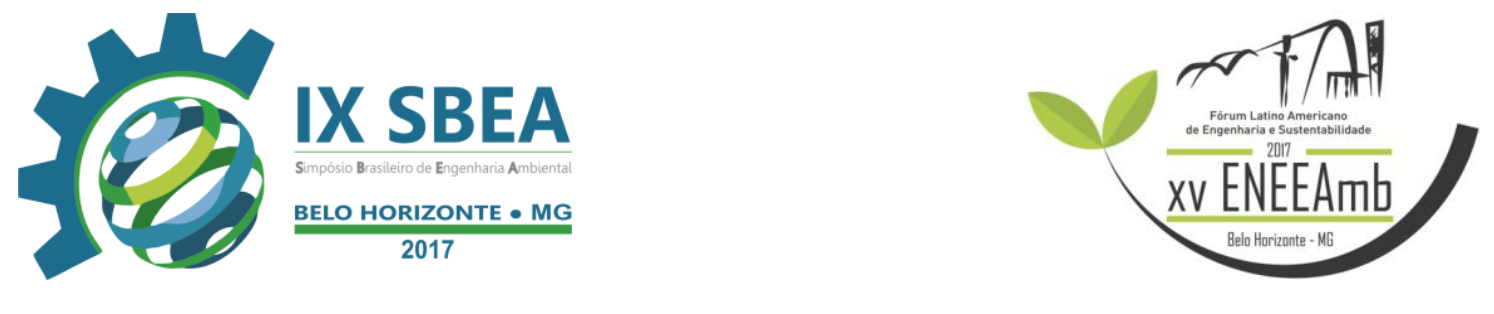

\begin{tabular}{|c|c|c|c|c|}
\hline $\begin{array}{l}\text { P5 - Bairro Santa } \\
\text { Felicidade }\end{array}$ & Ausência & Ausência & Ausência & Ausência \\
\hline P6 - Bairro Redondo & Ausência & Ausência & Ausência & Ausência \\
\hline $\begin{array}{l}\text { P7 - Bairro Princesa } \\
\text { Isabel }\end{array}$ & Ausência & Ausência & Ausência & Ausência \\
\hline
\end{tabular}

As análises para detecção de microrganismos patogênicos como bactérias, vírus e protozoários é muito onerosa e difícil, isso por apresentar pequena concentração no meio. Portanto, a verificação é realizada através de microrganismos indicadores como os coliformes, que estão relacionados às fezes de animais de sangue quente (MIZUTORI, 2009).

A identificação para verificar os coliformes é realizada facilmente através de análises laboratoriais, onde as bactérias pertencentes a esse grupo apresentam pontos de coloração diferentes permitindo visualizar as unidades formadoras de colônias, isso ocorre pelo fato das bactérias fermentarem a lactose do meio de cultura através de enzimas diferentes (BRASIL, 2006).

\section{Conclusão}

Diante dos resultados obtidos através das análises realizadas, observou-se que $36 \%$ das análises de turbidez apresentaram concentrações superiores a 5 UNT, visto que no mês de junho as concentrações de turbidez foram superiores ao mês de julho, e ambos os meses apresentaram valores acima do valor máximo permitido. Desta forma, pode-se afirmar que a água fornecida aos usuários da cidade de Alta Floresta D’Oeste - RO quanto a turbidez no período estudado, não atendia os padrões de potabilidade da Portaria $\mathrm{n}^{\circ}$ 2.914/2011 do Ministério da Saúde.

Em relação ao estudo realizado sobre $\mathrm{pH}$, coliformes totais e E.coli, pode-se constatar que o sistema de tratamento e rede de abastecimento do SAAE se mostrou eficaz, visto que $100 \%$ dos pontos amostrais estavam dentro dos padrões de potabilidade estabelecido pela portaria comparada. 


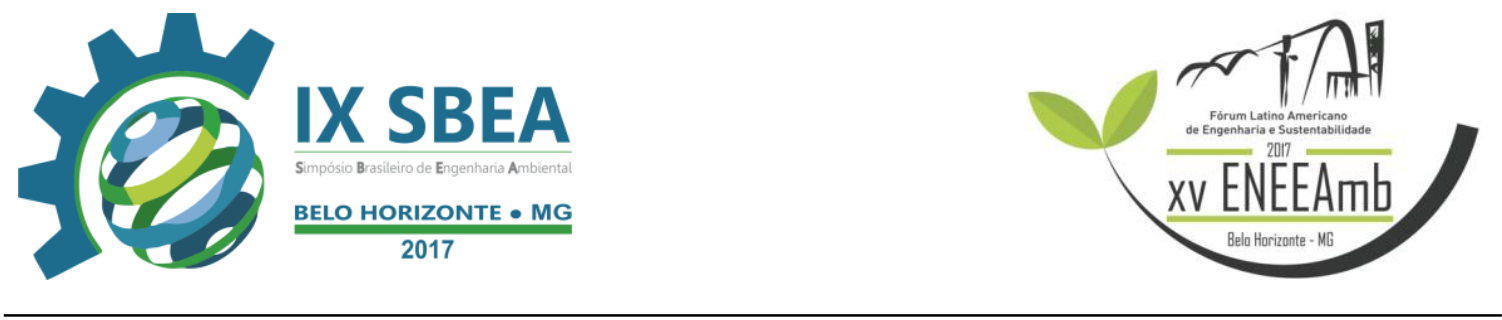

\section{Referências Bibliográficas}

ABAS, Associação Brasileira de Águas Subterrâneas. Águas subterrâneas, o que são?. Disponível em: <http://www.abas.org.br/educacao.php>. Acesso em: 30 de maio de 2015.

APHA. Standard Methods for the Examination of Water and Wastewater. Washington: APHA, 1995.

BAIRD, C. Química ambiental. 2. ed. Porto Alegre: Bookman, 2002.

BRASIL. Ministério da Saúde. Secretaria de Vigilância em Saúde. Vigilância e controle da qualidade da água para consumo humano. Brasília: Ministério da Saúde, 2006.

BRASIL, Ministério da Saúde. Portaria $n^{\circ}$ 2914, de 12 de dezembro de 2011. Dispõe sobre os procedimentos de controle e de vigilância da qualidade da água para consumo humano e seu padrão de potabilidade. Brasília: Diário Oficial da República Federativa do Brasil, 2011.

FUNASA - FUnDAÇÃO NACIONAL DA SAÚDE. Manual Prático de Análise de Água. Brasília, $4^{\circ}$ edição, 2013.

HELBEL, A. F. Análise da qualidade das águas subterrâneas no perímetro urbano de Ji-Paraná / RO - Brasil. Ji-Paraná, Rondônia, 2011.

LIBANIO, M. Fundamentos de qualidade e tratamento de água. 2.ed. São Paulo: Átomo, 2008. 444p.

MARQUES, F. C.; CAVALCANTE, P. R. S.; BARBIERI, R. Qualidade das águas subterrâneas da área urbana no município de Santa Helena (MA). In: CONGRESSO BRASILEIRO DE ÁGUAS SUBTERRÂNAS E ENCONTRO NACIONAL DE PERFURADORES DE POÇOS, 16. e 17., 2010, São Luís.

MIZUTORI, I. S. Caracterização da qualidade das águas fluviais em meios periurbanos: o caso da bacia hidrográfica do rio Morto - RJ. Rio de Janeiro: PEAMB/UERJ, 2009. Dissertação (Mestrado em Engenharia Ambiental), Programa de 


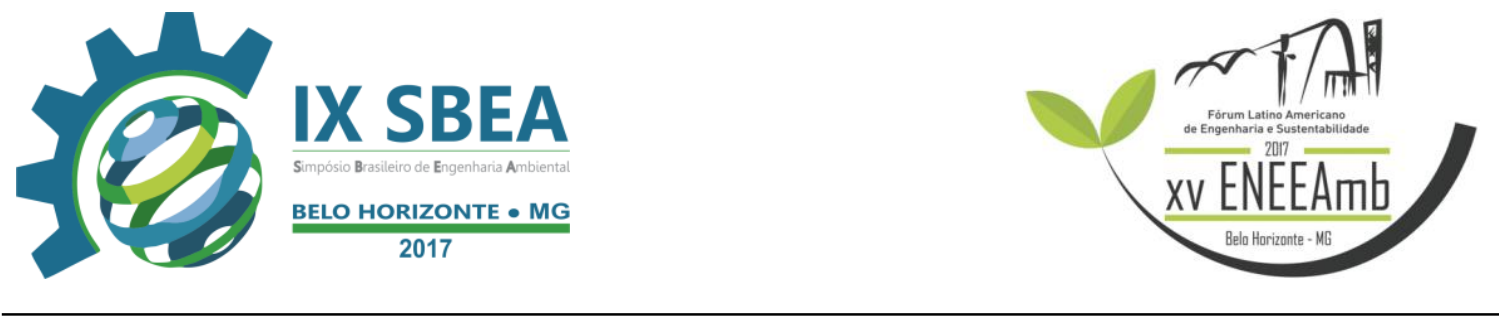

Pós-Graduação em Engenharia Ambiental, Universidade do Estado do Rio de Janeiro, 2009.

NEVES, D. V. F.; NASCIMENTO, C. E. Qualidade da água bruta e tratada disponibilizada no campus urbanova. São José dos Campos, Paraíba, 2012.

SIQUEIRA, L. P.; SHINOHARA, N. K. S.; LIMA, R. M. T.; PAIVA, J. E.; FILHO, J. L. L.; CARVALHO, I. T. Avaliação microbiológica da água de consumo empregada em unidades de alimentação. Ciência e Saúde Coletiva, Rio de Janeiro, v. 15, n. 1, p. 6366, 2010. 